\title{
Improving Project Management Process in Municipality Based on SWOT Analysis
}

\author{
S. Mohammad Arabzad and Hadi Shirouyehzad
}

\begin{abstract}
Currently, Project management concept developments alongside the organizations requirements in applying this knowledge, providing a method (methods) for designing and implementing a better PM is deemed necessary. Thus, every effort should be made in order to improve, plan and execute projects. The results will include increased quality of work, employer and customer satisfaction, reduction of costs and saving time. In this article various perspectives on Critical Success Factors, which affect the success level of a project, have been gathered using Strategic Management approach. Then the required data for solving these problems in projects using SWOT (Strength, Weakness, Opportunity, and Threat) is obtained by questioning a panel of experts. Then by analyzing the results, an efficient "flowchart" is presented in which the design procedure, deployment and implementation of the projects is demonstrated by considering the Strategic Management approach. Results show that by using information from SWOT matrix, many project threats and weaknesses are in fact, reversible.
\end{abstract}

Index Terms-Critical success factors (CSFs), Municipality, Project management, Roadmap, SWOT analysis.

\section{INTRODUCTION}

In order to achieve their strategic goals, organizations define and run projects. This firstly will be performed by developing general goals of organization based on strategy, then by defining programs and finally planning the projects [1]. However these projects with strategic objectives are more consistent and have greater efficiency. It leads to better and faster achievements and provide organizational goals. Project Management (PM) processes have witnessed a lot of improvements and major changes. The major developments in the field of PM have occurred in exchanging traditional attitudes in the PM for a modern attitude. Lack of resources, magnitude and complexity of project organization, increases in project size, the formation of large companies for large projects, and the unique nature of these projects have been among the reasons for employing new methods for project management. For instance, study results has shown 30 percent of all projects have been stopped halfway and more than half of them have used 190 percent of the approved budget or/and their completion time has faced with 220 percent delay [2]. So today one of the most important

Manuscript received May 17, 2012; revised June 19, 2012.

The authors are with Department of Industrial Engineering, Najafabad Branch, Islamic Azad University, Isfahan, Iran (e-mail: m.arabzad@yahoo.com; hadi.shirouyehzad@gmail.com). competitive advantages of organizations is efficiency in PM. To improve this competitive advantage, one of the requirements is that all organizations audit their projects and their strengths and weaknesses. They should undertake initiatives to implement quality, as soon as possible to compensate for their deficiencies. This will be used against falling behind global competition [3]. Considering projects as a temporary organization, in the initial stage, intensity of each project is required to design their own organization [4]. These developments have yielded a better success rate in relation to construction projects compared to other projects. The result of recent efforts has been codifying and publishing procedures and standards of PM.

In this research, Critical Success Factors (CSFs) affecting the success of projects have been gathered from different perspectives. According to the list of CSFs that were prepared for the project and also the SWOT matrix of cases in the municipality, a comprehensive and practical flowchart was designed for projects to cover the weaknesses and the best forms of Strength to be used and also considering the opportunities and threats properly. On the other hand, it should be able to reduce time and financial deviations and run projects with the highest efficiency and effectiveness. The Suggested flowchart included initial stages of a project from the start to final stages.

The paper is structured as follows: first the required definitions, key factors in the success of projects will be expressed. Then, factors that municipalities have been adjusted are expressed. SWOT table for these results is shown. Then, using information from this table, a reform proposal for the PM is presented.

\section{LITERATURE REVIEW}

\section{A. Project}

There are various definitions for the project. Projects include activities that should be completed within a certain timeline and budget, meeting a certain level of quality [5] According to ISO 10006 standards, PM is "planning, organizing, monitor-ring, controlling and reporting all aspects of a project and motivating all the people involved in order to achieve the project objectives" [6]. PMBOK defines projects in this way: "A project is a temporary effort undertaken to develop (create) a unique product or service" [7]. A different definition of project is that: "A project is a temporary organization that is established by the substrates of that organization to perform its mission" [8]. 


\section{B. Project Management}

$\mathrm{PM}$ is a series of management discipline and methods that if utilized properly during a project, will raise the probability of delivering good results [9]. PM is a way for the appropriate use of human work force, machinery and money in order to reach the final goal minus any errors within the first run. PM literature suggests that a senior manager's support is a critical mission and that its effectiveness presence is influential in the success of the project $[10,11]$. It is essential to notice that PM is the only way that can ensure us of performing projects on time. PM methods should focus simultaneously on people, procedures and technology, and concentrations ought to be changed from PM to project leadership [12]. Shenhar and Dvir [13] have expressed that the PM differently depending on the project has been done.

\section{Project Success Models}

In key factors associated with success several models and definitions in PM literature are presented. Shenhar, Levy and Dvir [14] proposed project efficiency, impact on customers, success in business and provision for future evaluations as main aspects of successful projects. Morley [15] believes that the PM triangle with three vertices timing, cost and technical performance are the best tools for diagnosis and determine the success or failure the project. Couillard [16] makes classification risks facing the project included three groups of risks associated with technical performance, risks of allocation or budget estimates and project schedule risks. In the end, most researchers agree that projects have a common nature in mainly four basic characteristics including limited resources; time scheduling, certain quality standards and a range of complex interactive activities [17].

\section{Strategic Management}

The Basis of a strategic planning for a project is the aims and ideals and the general criteria of success and failure of that project. SM widely is applied by institutions in order to endure adverse market competition. Many approaches and techniques could be used to analyze the strategic issues in the SM process [18]. One of these techniques is SWOT analysis which organizations use it to implement its strategic objectives and identify all the factors involved in making decisions. SWOT analysis is an important tool for decision support and is generally used for systematic analysis of internal and external environments of organizations [5-7]. Strengths and weaknesses are assessed by the internal environment; while opportunities and threats are assessed by the external environment [22].

\section{E. Critical Success Factors}

Searching previous studies indicate that the concentration of key factors identified for achieving project success, moved from purely technical factors to managerial and organizational factors over time. At first, the idea of identifying and applying CSFs in 1961 by Ronald Daniel was designed. Then this concept was effectively extended in 1980 by Rockart. According to his definition: "CSFs, pointing to limited areas in any project or business and if they lead to desirable results, ensure performance and competitive advantage for organizations to a good will" [23]. In 1980's and 1990's, quality of planning and delivery were identified as important issues and lists of CSFs considering organizational aspects and stakeholders became common. A project will achieve complete success when it is run on schedule, within the determined budget and carries technical and qualitative characteristic and has ultimately presented customer satisfaction. A low percentage of projects have achieved success by this definition [24].

Although the causes of success and failure of projects has become became the subject of many studies, but researchers have so far provided a comprehensive list of these reasons and no consensus has been achieved. Study is done to identify reasons for success and failure of projects and introducing "flowcharts" for practical purposes intended to promote the organization.

\section{MethodolOGY}

It is evident that for reaching success in any matter, the main question is that what factors influence the success? Which of these factors are strengths and which of them are weaknesses and how do these factors affect the success of our project? In this paper, different factors were considered from different viewpoints of recent authors. All of these factors lead to long list of key factors of success from different angles. These factors were classified into six categories and the selection was made according to different stages of PM, requirements before project planning, project and contractor selection, set contracts, project execution and monitoring project. Table I shows factors that affect the success of the project in categories mentioned. The next step was to adjust these factors to municipalities. The objective of this effort was to find out that which of these factors has been component strengths, weaknesses and opportunities and threats to municipal projects so far. The best responsive reference was civil deputies that have involved closely in each of the projects. In fact, these persons have touched the various deviations, the strengths and weaknesses and also deficiencies and shortcomings. Collecting data was designed to gain the most information from these individuals. Interview methods, despite several problems that were ahead were identified the best method for data collection. During interviews these factors were explained and the deputies' mayor expressed shared their experience and key points that were in their mind. In order to create more focused and complete analysis of these mentioned factors, the SWOT table was designed. After interviewing people who became involved with the project in the municipality, the mentioned factors were adjusted. According to these definitions, these factors are divided into the four main strengths, weaknesses, opportunities, and threats. In general, we can say that any project can be successful by removing weaknesses, considering threats, maintaining existing strengths and utilizing opportunities. 
TABLE I: PROJECT SUCCESS FACTORS [25-29]

Requirements Before Planning

Project Planning

$\checkmark$ SM tool to maintain a balance between the goals and desired interests.

$\checkmark$ SM tool to ensure access to ideal, vision and goals.

$\checkmark$ Risk management and organizational thinking tool for managing challenges and natural hazards.

$\checkmark$ Develop team working culture and rely on the collective wisdom.

$\checkmark$ Approval precept to encourage and use of techniques to improve efficiency.

$\checkmark$ Choose an experienced team with relevant expertise.

$\checkmark$ Selection of technical, honest, open minded consultant.

$\checkmark$ Coordinate schedule with the project financing process.

$\checkmark$ Consider and record possible reasons for delay in the critical tasks and how they impact on the project.

$\checkmark$ Proper coordination between the segments of tender documents, contract and contractor's claims.

$\checkmark$ Good coordination and communication and information flow between the design engineer, stakeholder, consulting engineers and contractors.

$\checkmark$ Active use of Total Quality Management (TQM) and Quality Assurance (QA).

$\checkmark$ Using advanced PM techniques such as Engineering Procurement Construction (EPC).

$\checkmark$ Use standards for people engaged in the project.

$\checkmark$ Timely delivery of funds for anticipated expenses.

$\checkmark$ Using Management Information System (MIS) to cover team information vacuum. $\checkmark$ Identify Project risks through brainstorming, Check lists, interview, SWOT matrix, and cause and effect diagram.

$\checkmark$ Identify 3 main characteristics of the project (goal, budget and due date).

$\checkmark$ Assess potential bottleneck in access to scarce resources, data, etc., leading to delays in projects.

$\checkmark$ Investigating non-compensable delays (of natural causes, etc.) and having a plan to deal with them.

$\checkmark$ Research, registration and planning for non-face non-negligible delays (lack of coordination and adequate labor utilization, delays, faulty operation).

$\checkmark$ Considering seasonal and weather conditions and economic situation.

$\checkmark$ Considering the uncertainty of cost and time in certainty space planning.

$\checkmark$ Inquire Expert opinion about uncertainties.

$\checkmark$ Identifying complete description of processes (instructions, goals, resources, output, etc.).

$\checkmark$ Consider deviation of time to start and to finish.

$\checkmark$ The role of outsourcing in profit and its actions if needed.

$\checkmark$ Considering the potential financial claims (for extra work, damages, etc.).

$\checkmark$ Value engineering (VE) tool to identify and remove unnecessary costs

$\checkmark$ Identify CSFs to focus, better control and increase chances of success.

$\checkmark$ Planning to deal with the major cause of failure in projects (changes in situations, supply disruption in communication and information flow)

$\checkmark$ Problem solving techniques to identify project problems.

$\checkmark$ Projecting a single methodology for managing all projects.

$\checkmark$ Identify Project owner's needs.

\section{Project and Contractor Selection}

$\checkmark$ Careful selection of project and engineering design in order to avoid changing plans during execution.

$\checkmark$ SM tool to select Projects (guaranteed to be in line with the objectives)

$\checkmark$ SM tool to identify priority projects and choose "choose the excellent among the rest".

$\checkmark$ Select the best contractor for the project and consider its significant role in the success and failure of a project.

$\checkmark$ Identification and selection of best contractors based on contractor background investigation.

$\checkmark$ Due to the short and long-term objectives in selecting priority projects.

\section{Set Contracts}

$\checkmark$ Complete and integrated contracts in three parts; before contract, set contract and managing claims.

$\checkmark$ Consider risks and factors increasing time and cost in contract.

$\checkmark$ Consider demands, authorities, duties, commitments and responsibilities of parties to contract in the technical aspects, legal and finance.

$\checkmark$ Create preparedness in organization for dealing with any claims.

$\checkmark$ Placing compensation clause on the contract (delays at the time of completion, inability to complete the project.)

$\checkmark$ Determines the amount of delay penalties and rewards speed exactly

$\checkmark$ Considering discussing maintenance in the contract plans.

\begin{tabular}{|c|c|}
\hline Project Execution & Monitoring Project \\
\hline$\checkmark$ Considering risks in project implementation. & $\checkmark$ Quality control supervisor. \\
\hline$\checkmark$ Collecting, storing and documenting data from projects in the database. & $\checkmark$ Define performance indicators and deliver projects based on it. \\
\hline $\begin{array}{l}\checkmark \text { Assess potential bottleneck in access to scarce resources, data, etc., } \\
\text { leading to delays in projects. }\end{array}$ & $\begin{array}{l}\checkmark \text { Regular visits from the project to ensure proper implementation of } \\
\text { projects by contractors. }\end{array}$ \\
\hline$\checkmark$ Careful planning in project resource allocation and resource leveling. & $\begin{array}{l}\checkmark \text { Accurately in convey agendas and considering the financial effect of } \\
\text { instructors and changes by supervisor. }\end{array}$ \\
\hline $\begin{array}{l}\text { Manufacturing Resource Planning (MRP) tool to reduce high costs at the } \\
\text { beginning of the project, reducing the time to order materials, and the } \\
\text { existence of liquidity necessary when purchasing materials and } \\
\text { equipment. }\end{array}$ & $\begin{array}{l}\checkmark \text { Permanent monitoring system to monitor technical issues, and contract } \\
\text { enforcement. } \\
\checkmark \text { Planning monitoring activities to reduce delays associated with "waiting } \\
\quad \text { supervision." }\end{array}$ \\
\hline $\begin{array}{l}\checkmark \text { Considering uncertainties in time (the unavailability of raw materials, } \\
\text { timing and estimates error, administrative errors, climate change). }\end{array}$ & $\begin{array}{l}\checkmark \text { Registration Tips learned from all stages of projects for future use and } \\
\text { promotion processes. }\end{array}$ \\
\hline \multicolumn{2}{|l|}{$\checkmark$ Use of software PM to allocate, scheduling and control costs. } \\
\hline \multicolumn{2}{|l|}{$\begin{array}{l}\checkmark \text { Research, registration and planning for non-face non-negligible delays } \\
\text { (lack of coordination and adequate labor utilization, delays, faulty } \\
\text { operation). }\end{array}$} \\
\hline \multicolumn{2}{|l|}{$\begin{array}{l}\checkmark \text { Considering seasonal changes, weather conditions and economic } \\
\text { situation at the time of implementation activities. }\end{array}$} \\
\hline$\checkmark$ Spend appropriate time to buy resources and equipment. & \\
\hline$\checkmark$ Establish proper coordination between supplies and equipment. & \\
\hline
\end{tabular}




\begin{tabular}{|c|c|}
\hline Strengths (S) & Weaknesses $(\mathbf{W})$ \\
\hline 1. There are funds available for projects. & 1. Feasibility studies do not be precise and complete. \\
\hline 2. Having programs for the project (detailed urban plans, etc.). & 2. Not carefully predicting project duration. \\
\hline 3. Being flexible project budgets. & 3. Project risks not calculated and are not measured in the estimates. \\
\hline 4. Use of specialist for the implementation. & 4. Lack of regulatory Check list during project implementation. \\
\hline 5. Local, professional and experienced managers administer the city. & 5. Lack of programs to support the project after the final delivery. \\
\hline \multirow{9}{*}{$\begin{array}{l}\text { 6. With regard to training provided organizational Mature related to PM issues are } \\
\text { made. } \\
\text { 7. There are infrastructures to receive public comments before, during and after } \\
\text { completion of the project. }\end{array}$} & 6. Lack of documentation, archive and transfer of project experience. \\
\hline & 7. A long process of being approved. \\
\hline & 8. Lack of evaluation of contractors. \\
\hline & 9. There bottleneck work during the project stages. \\
\hline & 10.Lack of floating funds for urgent projects. \\
\hline & 11.Lack of quantitative criteria to identify qualified contractors. \\
\hline & 12. The foundation of municipal finance regulations is old (about 1949). \\
\hline & 13. Lack of proportion observers with the number of projects under the supervision. \\
\hline & 14. Neglecting in-service training for supervisors. \\
\hline Opportunities (O) & Threats (T) \\
\hline 1. There are ranks to ensure the ability of contractors. & 1. Lack of information from urban facilities and equipment. \\
\hline $\begin{array}{l}\text { 2. The spirit of interaction and cooperation with the municipal bodies in line with } \\
\text { the definition and implementation of municipal projects. }\end{array}$ & $\begin{array}{l}\text { 2. There are many social and cultural factors surrounding urban projects. } \\
\text { 3. Lack of variety in urban design projects. }\end{array}$ \\
\hline $\begin{array}{l}\text { 3. Participatory people's spirit towards the project proposal and to consider their } \\
\text { actions. }\end{array}$ & 4. Lack of urban cultural atlas (Age, demographic, cultural, etc.) \\
\hline $\begin{array}{l}\text { 4. There are specialist and experience contractors in line with management and } \\
\text { project control related to urban and municipal issues. }\end{array}$ & $\begin{array}{l}\text { 5. Lack of funds to provide important national and International projects } \\
\text { 6. There are special restrictions for natural and historic cities. }\end{array}$ \\
\hline 5. There is existing opportunity of ICT. & \\
\hline
\end{tabular}

Table II shows the factors found in successful implementation of Municipality's projects in the form of SWOT matrix. This flowchart prevents some weaknesses and

threats. Detailed steps of a flowchart have been shown in Fig. 1.

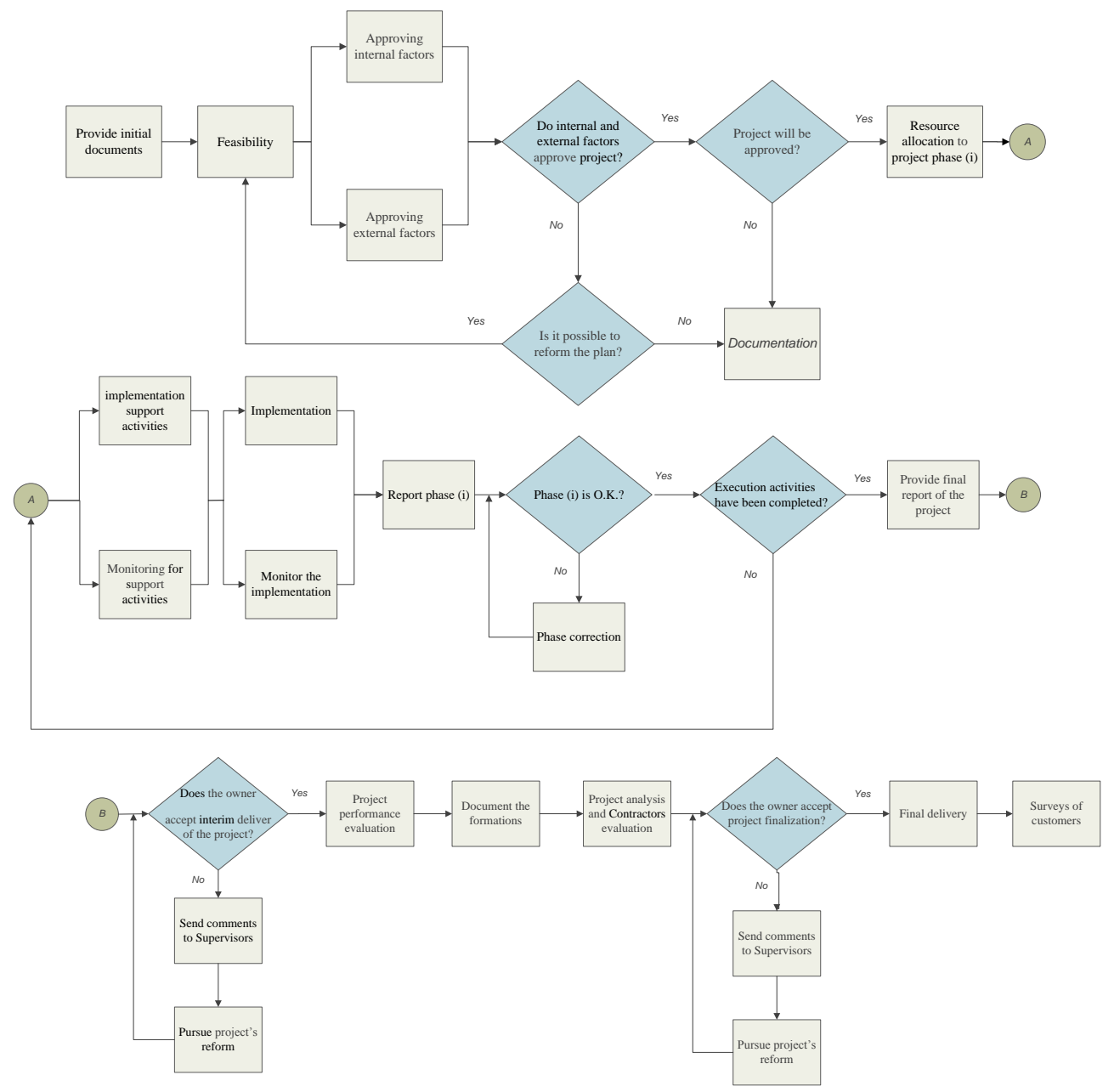

Fig. 1. Practical roadmap for project implementation 


\section{DisCUSSION}

Behind the scenes of each project there is the idea that has occurred in the mind of a person. These people are usually within the organization, because they highly engage with the matter. As previously mentioned municipalities are faced with large number of projects that must be executed. If municipal employees were responsible for defining and designing projects, we certainly would not be able to see a variety of projects in design (T3). This is an important threat to the town, while we can highly use existing opportunities in information and communication technology (O5) and also the spirit of collaboration to suggest projects $(\mathrm{O} 3)$.

What is identical in all projects is the Initial phase of researches and studies. In this phase, feasibility studies and financial forecasts will be done. This phase is so important that experts believe it is directly related to a project success. Even so about 30 percent of efforts to fully implement a successful project are necessary to carry out a research phase with experienced and knowledgeable managers (S5). So focusing on this phase can cover weakness 1, 2 and 3 . Another important trend to create a systematic process that should be considered is an appropriate interaction between internal and external organizational factors. Perhaps a project from the perspective of internal factors, but the contradiction is approved external factors such as state enterprise has.

Priority between the two cannot be allowed, for each in turn have great importance. So many times it has been cited that even large projects have failed due to lack of necessary coordination with the external organizational factors including: Lack of information from urban facilities and equipment (T1) and a lack of urban cultural atlas (T4), many social and cultural factors surrounding urban projects (T2), lack of funds to provide important national and International projects (T5), and special restrictions for natural and historic cities (T6). Fortunately the spirit of interaction and cooperation between cities had studied agencies with the authority (O2). If internal and external factors of the organization had approved the project, the project could be approved and if not, all documents and reasons of disapproval should be archived. Archive documents can be effectively useful in transferring the experience. If internal and external factors do not approve aspects of projects, reforms should be done to get execution license.

If the project is approved, the first action that must be done is resource allocation phases of the project. Phases of the project should be approved in feasibility studies. At this stage it is essential that managers cooperate in resource allocation to each phase which runs. Paying attention to this fact can reduce the bottleneck works that may be created during project implementation stage (W9). Many cases have been observed that there were adequate funds for project implementation (S1), but lack of timely allocation of credit to business has created a bottleneck phase. Another point is to have flexible budgets (S3) that have a significant effect in reducing the bottle-neck. Obviously successful implementation of activities without enough support will not be achieved. All activities and phases of the Project must have adequate support and supervision over them. These points in the projects have received lower respect. Most projects do not have a program to support credit activities
(W5). In monitoring the project, it should be mentioned that unfortunately less attention is paid to look this as an important issue. Institutions also usually do not consider specializations in service training for observers (W14). Thus after each phase of implementation and compliance with regulatory reporting implementation, it will be confirmed or if the case is unacceptable, will be modified to be finally confirmed. This process will be done for all phases of the project. The advantage of breaking projects into phases and approving each phase before the implementation phase is the following gradual progress project possible deviations of the cases predicted to severely reduced.

After all phases of the project are completed, final report of each phase and also the whole project can be collected. Now the issue is raised at this stage is whether the owner will accept delivering a temporary project or not. In some cases, due to neglecting of supervisors and contractors, a great gap might appear in the finished project and the desired one. In this case, a contractor should modify the project to get approval from the owner. If the owner verified the performance of the project, evaluation can be done from various aspects. This stage is one of the most important steps in the process of PM. Indeed, the project created with the goals set for this project is consistent but to what extent? Does the project have a considerable gap with the predicted time and budget? And many such questions. The answers to these questions with all project documents and amendments simply must not fail. Unfortunately, there is not enough attention to this problem (W6). There are very large projects without documentation and certificates which itself could create many problems. One of the advantages of documentation is providing necessary conditions for project and contractor analysis and evaluation. Usually the projects and contractors are not analyzed after execution (W8). This makes the reform experiences of each project is obtained and mistakes may not be repeated in the numerous upcoming projects.

If contractors are evaluated after the execution, they will be selected more properly in subsequent projects. In fact quantitative criteria will be obtained to identify qualified contractors (W11). If the selection of contractors has been done with quantitative criteria, specialized and experienced contractors will be selected $(\mathrm{O} 4)$. It has noted according to the ability of contractors to Managerial organization ensure action has to rank them. After this stage, the owner must decide about the project delivery. Obviously, using expert opinions in project analysis and evaluation, a contract owner can decide with a higher quality about the final delivery of the project. Surveying citizens is the last phase of the designed PM process and can be useful for future projects. Accomplishing this without an infrastructure for public comments (S7) is not possible.

\section{CONCLUSION}

According to the comprehensive CSFs collected and information from experts it can be claimed that the model of this article is comprehensive. It should be mentioned most organizations have PM process for their projects, but the quality of their process and that how much success is 
achieved with these process, rather than contemplation. In most organizations the existence of a long project approval process and lack of accurate and expert program can be a costly problem. The model not only gives a detailed plan of implementing to project managers, but also tries to reduce undesirable factors mentioned by experts. Finally, any attempt to create process perspective to PM can create mature organization that can make a good source for organizing events. Also it should be noted, adapting a provided model to PM approach phases could be a future research.

\section{REFERENCES}

[1] Project Management Institute, Inc., Organizational Project Management maturity model knowledge foundation, USA, 2003.

[2] J. Thomas, C. Delisle, K. Jugdev, and P. Buckle, "Selling Project Management to Senior Executives: The Case for Avoiding Crisis Sales," Project Management Journal, vol. 33, pp. 19-28, 2002.

[3] E. Nejabat and H. Nasseri, "Health assessment project: based on PMBOK ® Guide 2004 standard," The Second International Conference on Project Management, Tehran, 2005, 56-62.

[4] R. Gareis, Managing the Project Start, Gower Handbook of PM, Gower, 2000.

[5] M. R. Attaii and H. Mirzapour, "Applying strategic management in project selection; application of numerical models and non-numerical models", The first International conference on strategic management of projects, Tehran, 2004, pp. 15-21.

[6] Standard: ISO 10006, International Organization for Standardization, 2003, pp.20.

[7] Project Management Institute, Inc., A Guide to the Project Management Body of Knowledge (PMBOK Guide), 3rd ed., USA: Newton Square, 2004.

[8] E. S. Andersen, Rethinking PM-An Organisational Perspective, Harlow: Prentice-Hall, 2008.

[9] J. Glaser, "Back to basics managing IT projects," Healthcare Financial Management, vol. 58, pp. 34-38, 2004.

[10] K. N. Jha and K. C. Iyer, "Critical factors affecting quality performance in construction projects," Total Quality Management, vol. 17, pp. 1155-1170, 2008.

[11] R. Young and E. Jordan, "Top management support: Mantra or necessity?," International Journal of Project Management, vol. 26, pp. 713-725, 2008.

[12] K. Nidiffer and D. Dolan, "Evolving Distributed PM," IEEE Software, Vol. 22, pp. 63-72, 2005.

[13] A. J. Shenhar and D. Dvir, Reinventing PM, Boston: Harvard Business School Press, 2007.

[14] A. J. Shenhar, O. Levy, and D. Dvir, "Mapping the dimensions of project success," PM Journal, Vol. 28, pp. 5-13, 1997.

[15] C. Morley, Gestion d'un systeme d'information: principes, techniques, mise en oeuvre, Paris: Inter Editions, 1996.

[16] Couillard, J., "The role of project risk in determining PM approach," PM Journal, pp. 3-9, December 1995.

[17] R. Atkinson, "PM: cost, time and quality, two best guesses and a phenomenon, its time to accept other success criteria," International Journal of PM, Vol. 17, pp. 337-342, 1999.
[18] O. Dincer, Strategy Management and Organization Policy, Istanbul: Beta Publication, 2004.

[19] R. Stewart, S. Moamed, R. Daet, "Strategic implementation of IT/IS projects in construction: a case study," Automation in Construction, vol. 11, pp. 681-694, 2002

[20] J. Kangas, M. Kurtila, M. Kajanus and A. Kangas, "Evaluating the management strategies of a forestland estate-the S-O-S approach," Journal of Environmental Management, vol. 69, pp. 349-358, 2003.

[21] M. Kurttila, M. Pesonen, J. Kangas and M. Kajanus, "Utilizing the analytic hierarchy process (AHP) in SWOT analysis-a hybrid method and its application to a forest-certification case," Forest Policy and Economics, vol. 1, pp. 41-52, 2000.

[22] R. G. Dyson, "Strategic development and SWOT analysis at the University of Warwick," European Journal of Operational Research, vol. 152, pp. 631-640, 2004.

[23] J. Rockart and C. Bullen, A primer on critical success factors, Center for Information Systems Research Working Paper No 69. Sloan School of Management, MIT, 1981.

[24] R. Wysoki,Beck, R. and D. Crane, Effective PM, 1st ed., John Wiley \& Sons Inc, 1995.

[25] H. J. Dobbins, "Identifying and Analyzing Critical Success Factors," Program Management Journal, pp. 40-45, May-June 2002.

[26] H. Amoozad khalili, R. Tavakkoli-Moghadam and S. Ayani, "Projects strategic management in allocating limited resources simultaneously with implementing project," The first International Conference on strategic management of projects, Tehran, 2004, pp. 168-175.

[27] F. Davoodi and M. Khanzady, "Providing a method for calculating the time delay analysis considering reducing production project," The first International conference on strategic management of projects, Tehran, 2004, pp. 135-142.

[28] M. Jafari and N. Gandomi, "Role in the EPC contract to reduce project delays and increased profits," The first International Conference on strategic management of projects, Tehran, 2004, pp. 78-84.

[29] E. Ashthardyan, R. Abbas Nia and A. Afshar, "cost balance-Time inconclusive with regard to timing," The first International Conference on strategic management of projects, Tehran, 2004, pp. 53-60.

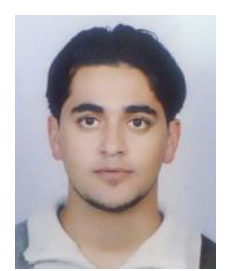

S. Mohammad Arabzad was born in Isfahan, Iran on 8 March 1987. He graduated in Iran 2009 and 2012 with BS and MS degrees, in Industrial Engineering at Najafabad Branch, Islamic Azad University, Isfahan, Iran. He is the author of more than 25 published papers at national and international levels in refereed journals and conferences since 2010.

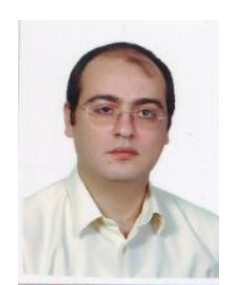

Hadi Shirouyehzad graduated in Iran 1999 and 2002 with BS and MS degrees, in Industrial Engineering. He achieved his $\mathrm{PhD}$ in Industrial Engineering in 2012 from the Research and Science Branch, Islamic Azad University, Tehran, Iran. Currently he is the faculty member of the Department of Industrial Engineering at Najafabad Branch, Islamic Azad University, Isfahan, Iran. He is the author of two books and more than 60 published papers at national and international levels in refereed journals and conferences since 2003 . 